\title{
La imagen de perfil en Facebook: identidad y representación en esta red social ${ }^{1}$
}

\author{
The Profile Picture on Facebook: Identity and \\ Representation on the Social Network
}

\author{
A imagem do perfil do Facebook: identidade \\ e representação nesta rede social
}

Rocío Rueda $0^{2}$
Diana Giraldo

Resumen

En el proyecto "Formas de (re)presentación en la red social Facebook", nos concentramos en la imagen de perfil del ecosistema comunicativo de dicha red social. No existe determinismo tecnológico o social en estas interacciones. En cambio, vemos que emergen nuevas formas de uso cotidiano de las tecnologías que están (re)configurando nuestros valores y nuestra cultura. Este artículo presenta en primer lugar los resultados del inventario y clasificación de 7200 imágenes de imágenes de perfil de usuarios de Facebook de 24 ciudades alrededor del mundo. Los criterios de clasificación se basaron inicialmente en un modelo que incluye representante, tratamiento, encuadramiento de la imagen (RTE). En segundo lugar, este artículo propone algunas pistas para estudiar las continuidades y transformaciones de la relación con la fotografía. Aunque nuestro estudio no se enfocó especialmente en jóvenes, es evidente que un número significativo de los resultados se refieren a este grupo poblacional, el cual está experienciando las tecnologías digitales como una respuesta a sus necesidades expresivas y a las exploraciones identitarias que caracterizan la vida de las sociedades modernas. Finalmente, presentamos algunas conclusiones sobre la integración de las tecnologías en la vida cotidiana.

Palabras clave: Subjetividad, socialización, Facebook, identidad, imagen.

\section{Abstract}

In the project 'Ways of Self-(re)presentation on the Facebook Social Network', we focus on the profile image and the entire communicative ecosystem. There is no technological or social determinism in these new forms of interactions. Instead, we see new subjectivities emerging from the contingency of everyday use of technologies where our values and culture are being (re)shaped. This text presents the results of the inventory and classification of 7,200 profile pictures of Facebook users from 24 different cities around the world. The classification criteria were initially based on a model which includes: entity, treatment and framing (ETF) of the image. This paper also proposes some clues to study the continuities and transformations of the uses of the photographic image. Although our study does not focus specifically on youth, we present a number of results in relation to this demographic group, which is experiencing digital ICTs as an answer to the expressive needs and identity explorations which characterize our modern social life. Finally, we introduce some conclusions about the integration of digital ICTs in everyday life.

Keywords: Subjectivity, socialization, Facebook, identity, image.

1 Este artículo retoma reflexiones derivadas de la investigación finalizada: “Formas de presentación de la persona en Facebook" (Código 5232). Proyecto formulado desde la Universidad del Valle que contó con la cooperación interinstitucional de la Universidad Pedagógica Nacional y la Universidad ICESI. En este equipo participaron como investigadores: Rocío Gómez, Diana Giraldo, Julián González, Viviám Unás, Armando Henao y Rocío Rueda Ortiz. Como monitores y colaboradores: Ana Paola Angulo, Natalia Cárdenas, Maryoli Ceballos, Mónica López, Juan Carlos Mora, Laura Parra, Jhony Velasco y Jonn Velasco. Una versión en inglés más extensa de este texto se encuentra en el capítulo de libro: Rueda, R. y Giraldo, D. (2014). "Profile image: ways of self(re)presentation on the Facebook social network". Saegret, B (Ed). Youth 2.0: Connecting, Sharing and Empowering. University of Antwerpen, Bélgica, Springer (en prensa).

2 Universidad Pedagógica Nacional, Bogotá, Colombia. Correo Electrónico: rruedaortiz@yahoo.com

3 Universidad del Valle, Cali, Colombia. Correo electrónico: giraldodiana@gmail.com 


\section{Resumo}

No projeto "Formas de (re)presentação na rede social Facebook", nós concentramos na imagem de perfil do ecossistema comunicativo de essa rede social. Não existe determinismo tecnológico o social nestas interações. Na mudança, vemos que emergem novas formas de uso cotidiano das tecnologias que estão (re)configurando nossos valores e nossa cultura. Este artigo apresenta em primeiro lugar, os resultados do inventário e classificação de 7.200 imagens de perfil do usuário de Facebook, de 24 cidades ao redor do mundo. 0s critérios de classificação basearam-se inicialmente num modelo que inclui representante, tratamento, enquadramento da imagem (RTE). Em segundo lugar, este artigo propõe alguns sinais para estudar as continuidades e transformações da relação com a fotografia. Embora nosso estudo não se enfocou especialmente em jovens, é evidente que um número significativo dos resultados se referem a esse grupo populacional, o qual está experimentando as tecnologias digitais, como uma resposta a suas necessidades expressivas e às explorações identitárias que caracterizam a vida das sociedades modernas. Finalmente, apresentamos algumas conclusões sobre a integração das tecnologias na vida cotidiana.

Palavras-chave: Subjetividade, socialização, Facebook, identidade, imagem.

Artículo recibido el 4 de febrero de 2015 y aprobado el 26 de junio de 2015

\section{Introducción}

En el presente artículo nos proponemos comprender una de las dimensiones de la construcción identitaria, la presentación de la imagen de sí, a partir de las imágenes de perfil publicadas en redes sociales como Facebook. Nuestro punto de partida es que mientras en las interacciones cara a cara las personas se presentan a sí mismas como si estuvieran desempeñando un rol, en Facebook se presentan por medio de "obras de arte", de una "opera mundana"4. Desde esta perspectiva, nos preguntamos: ¿cómo se pueden analizar estas "obras de arte", teniendo en cuenta no solo su función representativa y expresiva, sino como parte importante de un sistema de valores? Dado que no podemos identificar a priori las intrincadas relaciones e intenciones que la gente pone en juego cuando decide publicar una determinada imagen de perfil, decidimos entonces reconocer y clasificar los procedimientos formales detrás de la génesis de una imagen. Para estudiar dichos procesos, exploramos cómo los usuarios de Facebook usan - o no- ciertos recursos digitales en la captura y el tratamiento de su imagen, y, en consecuencia, cómo las decisiones técnicas se entrecruzan con las necesidades sociales.

Respecto a los procedimientos técnicos, pensamos que existen restricciones porque todas las características de la plataforma Facebook, incluso aquellas que parecen insignificantes, tienen una influencia en la manera como los usuarios despliegan sus perfiles.

4 Usamos la palabra opera, plural del término latino opus, que da origen a operari (operar, laborar), que significa trabajo. Aquí enfatizamos tanto en la acción (laborar, trabajar) como el producto (obra) mundano.
Pero también posibilidades porque de manera complementaria, los usuarios disponen de unos recursos que les permiten decidir qué y cómo presentarse a sí mismos. En este sentido, destacamos dos aspectos de la obra de Goffman (1959) que nos sirvieron de punto de partida: primero, el hecho de que las interacciones humanas no ocurren de manera directa, sino a través de símbolos que contienen información social relevante. Segundo, la idea según la cual la presentación del yo emerge de la interacción con otros; en consecuencia, el rol que se adopta está siempre socialmente situado. Esto nos permite decir que detrás de una imagen de perfil en Facebook hay dos tipos de procedimientos: uno que toma en cuenta las restricciones y posibilidades de la plataforma (affordances), y otro que toma en cuenta las restricciones y posibilidades sociales, en situaciones concretas.

En este artículo se presentan algunos de los resultados del estudio "Formas de presentación de la persona en la red social Facebook", el cual observó tanto las imágenes de perfil como el ecosistema comunicativo de dicha red social. Partimos de la idea de que no hay determinismo tecnológico ni social en estas nuevas formas mediadas de interacción. En cambio, vemos que emergen nuevas formas de uso cotidiano de las tecnologías que están (re)configurando nuestros valores y cultura. En la primera fase de la investigación nos concentramos en el inventario y clasificación de 7200 imágenes de imágenes de perfil de usuarios de Facebook. Los criterios de clasificación se basan en un modelo desarrollado anteriormente por Gómez y González $(2009,2013$, que incluye tres categorías: representante, tratamiento y encuadramiento de la 
imagen (RTE). Nuestra hipótesis es que a pesar de la multiplicidad de opciones técnicas y de representación, la gente se concentra en muy pocas. Por lo tanto, nuestra intención inicial fue encontrar las tendencias y similitudes en diferentes ciudades del mundo.

La segunda fase de este estudio estuvo basada en un trabajo etnográfico. Se realizaron entrevistas a usuarios de Facebook, así como observaciones de cuentas de dicha red social durante seis meses. Esta etnografía nos permitió comprender la dinámica entre lo off y on line en la presentación de sí, y la ecología de las piezas visuales, sonoras y textuales, encontradas en las páginas de Facebook de los participantes. Esta dinámica es la que nos permite considerar el uso de Facebook como unas opera. El presente texto solamente dará cuenta de una parte de esta fase etnográfica que corresponde a las entrevistas con las doce personas seleccionadas para tal efecto. En dichas entrevistas logramos profundizar en el sentido de la imagen, la fotografía en la vida de estas personas, así como las transformaciones del mismo en sus cuentas de Facebook.

\section{Marco teórico}

Desde un enfoque sociocultural, es decir, considerando las relaciones interpersonales y los intercambios simbólicos que allí se generan, la identidad comprende tres dimensiones: primero, una dimensión ligada a las intenciones de (re)presentación del individuo frente a los otros; segundo, una dimensión relacional asociada a las interacciones con el círculo social inmediato; y tercero, el conjunto de roles que asume y desempeña el individuo de acuerdo con el entorno en el que se encuentra. Crear una auto-imagen y presentarse ante otros es por tanto una combinación de elementos: símbolos, interacciones y contexto, este último es de especial importancia cuando hablamos de redes sociales digitales como Facebook. Consideramos que las interfaces digitales juegan un rol preponderante en las formas de auto-(re)presentación contemporáneas, pues son el soporte, tanto técnico como social, de múltiples formas de expresión y co-construcción identitaria. Facebook, o más precisamentela imagen del perfil, sería justamente solo una dentro de un amplio rango de posibilidades. En esta sección presentamos nuestro marco conceptual, basado principalmente en el interaccionsmo simbólico propuesto por Goffman. Sin embargo, incluimos otras contribuciones de la sociología, la semiótica y los estudios culturales.

\section{La presentación de sí en la vida cotidiana}

Nuestra idea sobre cómo la gente se presenta a sí misma en Facebook surge claramente del análisis microsociológico de Goffman (1959). En sus estudios, él describe la gente como actores (performers) en un teatro y las interacciones cara a cara como el esfuerzo por manejar las impresiones en frente de una audiencia:

While in the presence of others, the individual typically infuses his activity with signs which dramatically highlight and portray confirmatory facts that might otherwise remain unapparent or obscure. For if the individual's activity is to become significant to others, he must mobilise his activity so that it will express during the interaction what he wishes to convey. ${ }^{5}$ (Goffman, 1959, p. 29)

Así, para Goffman, la presentación del yo en la vida cotidiana es un constante trabajo de creación y negociación: las personas deben seleccionar y emplear cuidadosamente su fachada, es decir, gestionar tanto el decorado como la apariencia y los modales, de manera que su actuación resulte verosímil:

Fronts are that part of the individual's performance which regularly functions in a general and fixed fashion to define the situation for those who observe the performance. Front, then, is the expressive equipment of a standard kind intentionally or unwittingly employed by the individual during his performance. ${ }^{6}(1959$, p. 22)

5 “Mientras se encuentra en presencia de otros, el individuo comúnmente impregna su actividad con signos que destacan y representan dramáticamente hechos confirmativos que de otro modo podrían permanecer inadvertidos y oscuros. Ya que la actividad del individuo ha de llegar a ser significante para otros, este debe movilizarla de manera que exprese durante la interacción lo que él desea transmitir" (traducción elaborada para el presente artículo).

6 "La fachada es la parte de la actuación del individuo que funciona regularmente de un modo general y prefijado, a fin de definir la situación para aquellos que observan la actuación. La fachada es, entonces, la dotación expresiva de tipo corriente empleada inten- 
Así, la presentación del yo, en lugar de ser un estado, es un proceso dinámico que involucra una producción (a veces individual, otras veces colectiva) en la cual el autor invierte esfuerzo, tiempo y cuidado.

De modo similar, tal puesta en escena es observable en las redes sociales digitales. Sin embargo, no estamos interesadas aquí en extrapolar cada uno de los conceptos propuestos por Goffman. Nuestro interés es explorar la metáfora dramatúrgica ofrecida por este autor en su definición general como el manejo de impresiones en la presentación del yo. En este sentido, resaltamos dos aspectos de la presentación del yo en la cotidianidad que parecen ser relevantes en el análisis de la construcción de la autoimagen en las redes sociales: primero, el rol activo de quien desea presentarse a una determinada audiencia; segundo, el manejo de un equipamento simbólico-expresivo de acuerdo a un ambiente específico de interacción, el cual provee tanto posibilidades como restricciones materiales y sociales.

\section{La fotografía como una práctica cotidiana}

Frecuentemente, se observa una relación importante entre un estado de ánimo, una narrativa personal y las fotografías. Algunos escritores, como Barthes (1989), Benjamin (1973), y Sontag (2005), han planteado que la fotografía es esencialmente melancólica: una foto recuerda el pasado, se refiere a lo que se ha ido, y está asociada con la pérdida y la muerte; aun lo que parece ser una imagen alegre puede ser tomado como una evidencia de lo pasado, de lo que ya no está. Pero, ¿tiene la fotografía solo una función conmemorativa? Actualmente, nuevos significados le están siendo atribuidos. Tomar fotografías no es una práctica exclusiva de artistas y profesionales; esta actividad se ha extendido debido tanto a la diseminación de aparatos de bajo costo como a la llegada de nuevas plataformas de exhibición de las mismas. Por supuesto, Facebook no institucionaliza la fotografía como una práctica común, pero sí ofrece otras condiciones para la creación, publicación y distribución de imágenes en la vida cotidiana que no existían antes.

cional o inconscientemente por el individuo durante su actuación" (traducción elaborada para el presente artículo).
Algunas perspectivas de la semiótica y de la teoría de la fotografía nos permiten explorar ciertos aspectos de la relación intrincada entre la experiencia personal de la fotografía, los significados sociales de las prácticas cotidianas y el uso de tecnologías de la imagen emergentes. Por ejemplo, Roland Barthes (1989) enfatiza la inseparabilidad de la imagen de su referente; así, la imagen y el objeto que esta describe son de la misma naturaleza. Para Barthes, el mensaje es en consecuencia un mensaje sin un código. Esta idea nos lleva a pensar cómo hoy los usuarios de Facebook hacen parte de un espacio comunicativo donde no hay un significado único sino múltiples significados, donde los autores nacen simultáneamente con sus opera. El autor no es reemplazado por otro que precede o transciende su trabajo. Esto se explica porque la acción de tomar fotos ya no consiste en grabar o representar algo, sino en lo que la pragmática denomina un acto performativo.

En contraste, la perspectiva de Benjamin se concentra en activar el pasado en el presente, pues para él nada desaparece para siempre; los trazos del pasado pueden ser redescubiertos y puestos en uso. Así, es posible pensar traer el pasado al presente y como anticipación del futuro. De hecho, como Roberts (2011) plantea, las fotografías y el fotografiar (un retrato profesional o una selfie en una cámara de celular) puede estimular la memoria, el recuerdo de personas, de eventos o de objetos asociados a experiencias emocionales y sensuales las cuales están situadas dentro de pensamientos, sentimientos y circunstancias actuales. El entorno que ofrecen las redes sociales como Facebook aprovecha esta nueva condición de nuestras sociedades y la acelera. Dicha aceleración se relaciona además con la necesidad de actualizar constantemente la imagen de sí, al parecer motivada por un deseo permanente de superarse a sí mismo frente a una audiencia que funciona como apoyo ( $I$ like it) pero también como crítica. Así, las fotografías proveen "una gramática y una ética de la visión", como destaca Sontag (2005). La fotografía, como objeto y como práctica social, desempeña un rol importante en la construcción del presente y del futuro, una temporalidad que se caracteriza en las redes sociales por la inmediatez, la fugacidad, la interactividad, el performance, en suma, características que parecen ser 
condiciones de las subjetividades contemporáneas y de sus tecnologías.

Como complemento de esta comprensión de la fotografía, consideramos que Sennett (2009) nos aporta otra noción importante: la de artesanía. Esta se refiere tanto al deseo como a la habilidad para realizar bien un trabajo. De esta manera Sennett amplía el materialismo cultural para incluir las sensaciones y los misterios que surgen de las cosas materiales en sí mismas; las maneras en las cuales el pensamiento abstracto se desarrolla a través de la actividad práctica; las formas de comportamiento social que emergen de la experiencia física compartida. Sennett reconoce las satisfacciones del hacer físico como una parte necesaria del ser humano. Necesitamos trabajo artesano como una vía para mantenernos a nosotros mismos enraizados en la realidad material, y al tiempo proveer un balance entre un mundo que sobre estimula las habilidades mentales. Es en este sentido que vemos la imagen de perfil como un trabajo material, como una rutina práctica y al mismo tiempo, como una experiencia individual y colectiva.

\section{Identidad, jóvenes y medios digitales}

De acuerdo con Van Dijck:

The digital evolution that has shaped personal photography is anything but an exclusive technological transformation. Rather, the shift in use and function of the camera seems to suit a more general cultural condition that may be characterized by terms such as manipulability, individuality, communicability, versatility and ease of distribution. This cultural condition has definitely affected the nature and status of photographs as building blocks for personal identity. ${ }^{7}(2008$, p. 70$)$

Esta autora nos lleva a considerar los diferentes estudios que se focalizan en los aspectos culturales

7 Traducción: La evolución digital que ha dado forma a la fotografía personal es cualquier cosa menos una exclusiva transformación tecnológica. Más bien, el cambio en el uso y la función de la cámara parece satisfacer una condición cultural más general que puede caracterizarse por términos como manipulabilidad, individualidad, comunicabilidad, versatilidad y facilidad de distribución. Esta condición cultural ha afectado sin duda la naturaleza y el estado de las fotografías como bloques de construcción para la identidad personal. de los medios digitales. Entre el extenso y diverso campo de estudios sobre juventud, identidad y uso de medios digitales, encontramos que la interpretación de los estudios culturales sobre la apropiación de Internet en la vida cotidiana es muy útil. En este grupo resaltamos los trabajos de Buckingham (2008) y Livingstone (2011). Como estos autores sugieren, los medios digitales proveen hoy a las generaciones jóvenes de recursos simbólicos para expresarse ellos mismos y construir sus propias identidades. Aunque nuestro estudio no se enfocó especialmente en jóvenes, es cierto que este grupo poblacional está viviendo con mayor intensidad los medios digitales como una manera de responder a las necesidades expresivas y a las exploraciones identitarias que caracterizan nuestra vida social moderna. Al respecto, el concepto de "reflexividad" que está en el corazón de la teoría de Giddens es clave. La reflexividad puede ser definida como un proceso de autodefinición que depende del monitoreo, reflexión de información psicológica y social acerca de las posibles trayectorias de vida. La reflexividad de la vida social moderna consiste, según este autor, en el hecho de que "las prácticas sociales están constantemente examinadas y reformadas a la luz de la información recibida a través de aquellas prácticas, alterando así constitutivamente su carácter" (1991, p. 28). Como muchos otros autores, Giddens observa la identidad como algo fluido y maleable, en vez de algo fijo. Richard Jenkins (1996), además, considera que la identidad es una materia fluida y contingente, algo que nos acompaña prácticamente a través de los resultados de las interacciones y negociaciones con otras personas.

Por lo anterior, nos resulta más apropiado hablar de identificación que de identidad. En Facebook, la identidad involucra mucho más que un acto voluntario de los usuarios puesto que hay mucha información que "otros" (amigos, empresas de publicidad) pueden proveer. Así, la construcción de la autoimagen en esta red social parece ser mucho más compleja que en las interacciones cotidianas. Como Cardon (2008) plantea, la identidad digital es una coproducción donde las estrategias de la plataforma y las tácticas de los usuarios se cruzan. De hecho, las producciones realizadas por los usuarios de Facebook requieren tanto de 
una manipulación técnica de la interfaz como de una actividad social de intercambio permanente con otros miembros de la red. En otras palabras, es necesario tener en cuenta, y en el mismo nivel, las dimensiones técnicas y sociales, ya que la presentación de sí mismo en las redes sociales digitales articula estrechamente la arquitectura del sitio y los cálculos que los usuarios hacen para producir una mejor impresión de sí mismos. Dicho de manera breve, en Facebook hay elementos de la identidad personal que son producidos $\mathrm{y}$, sobre todo, registrados por los otros, y los usuarios deben calcular y anticipar esto también.

Las redes sociales no solo explotan el aspecto relacional de la web, invitándonos a conectarnos y comunicarnos con otros, como ambientes comunicativos participativos, sino que estos también nos animan a crear. Ahora bien, esta participación es altamente autobiográfica. Cardon (2008) sugiere que, dentro de la lógica expresionista de la web, la identidad de las personas se encuentra cada vez más depositada y distribuida en sus obras y en los productos de esas actividades que se exhiben a los otros; se trata de producciones personales que difícilmente pueden ser separadas de su creador, en cuanto que ellas son testimonio de una singularidad biográfica. Dicho en pocas palabras, los usuarios de Internet están siendo invitados a ser parte de un rango amplio y variado de sitos y aplicaciones multimedia que requieren la construcción de una cuenta personal y de una imagen de perfil.

\section{Metodología}

\section{Primera fase: selección y clasificación de las imágenes de perfil}

De noviembre 2011 a mayo de 2012, realizamos la selección y clasificación de 7200 imágenes de perfil de Facebook ${ }^{8}$ en 24 diferentes ciudades del mundo (300 imágenes por ciudad). Los criterios de selección por ciudad utilizados fueron: a) alto grado de urbanización e infraestructura para el acceso a Internet; b) estilo de vida metropolitano, altos flujos migratorios y pobla-

8 En ese momento Facebook no había implementado el modo timeline (biografía) que permite no solo subir una imagen de perfil sino una imagen de portada de la página personal. ciones con alto contraste cultural; c) porcentaje alto de nuevos usuarios de Facebook en los años recientes, y d) particularidades sociales, políticas o culturales. Así, incluimos: Bogotá, Buenos Aires, Caracas, México D.F., Habana, São Paulo, Chicago, Montreal, New York, Toronto, Berlín, Londres, Madrid, Paris, Roma, Beijing, Bombay, Islamabad, Tel Aviv, Pyongyang, Tokyo, Johannesburgo, Nairobi y Sidney. Todas las imágenes fueron seleccionadas de perfiles públicos siguiendo una lista aleatoria que provee el navegador de Facebook luego de introducir el nombre de la ciudad.

Estas imágenes fueron clasificadas según un modelo de clasificación de imágenes (representante, tratamiento, encuadramiento, RTE), propuesto en un estudio previo (Gómez y González, 2009) basado en algunas categorías conceptuales y funcionales de los sistemas dinámicos no lineales (atractores, autoorganización, fase, transiciones, trayectorias) y refinado con el desarrollo del presente proyecto de investigación. Cada categoría es descrita por cuatro tipos que resultan de la combinación de dos variables, como se explica a continuación:

Representante ( $\mathrm{R}$ ) se refiere a lo que aparece en la imagen. La primera variable de esta categoría indica si la imagen de perfil muestra una figura humana o un objeto (no humano). La segunda variable determina si la imagen brinda alguna información o huella biográfica en el perfil del usuario. En este sentido, usamos el término bio-grafo. La tabla 1 ejemplifica los 4 tipos de entidades que resultan del cruce de las variables mencionadas 9 .

Tratamiento ( presentar la imagen de modo natural o artificial. En esta categoría, la primera variable oscila entre la presencia o ausencia de huellas de intervención. Nos referimos a la intervención como manipulación o edición digital de la imagen. La segunda variable clasifica la imagen según la escenificación, es decir, cuando se ha tenido la intención de ser espontáneo o cuando por el contrario hay una explícita manipulación del escenario. La tabla 2 muestra ejemplos de cada uno de los cuatro tipos de tratamiento.

9 Todas las imágenes utilizadas en el artículo tienen autorización de sus propietarios. 
Tabla 1. Tipos de representante

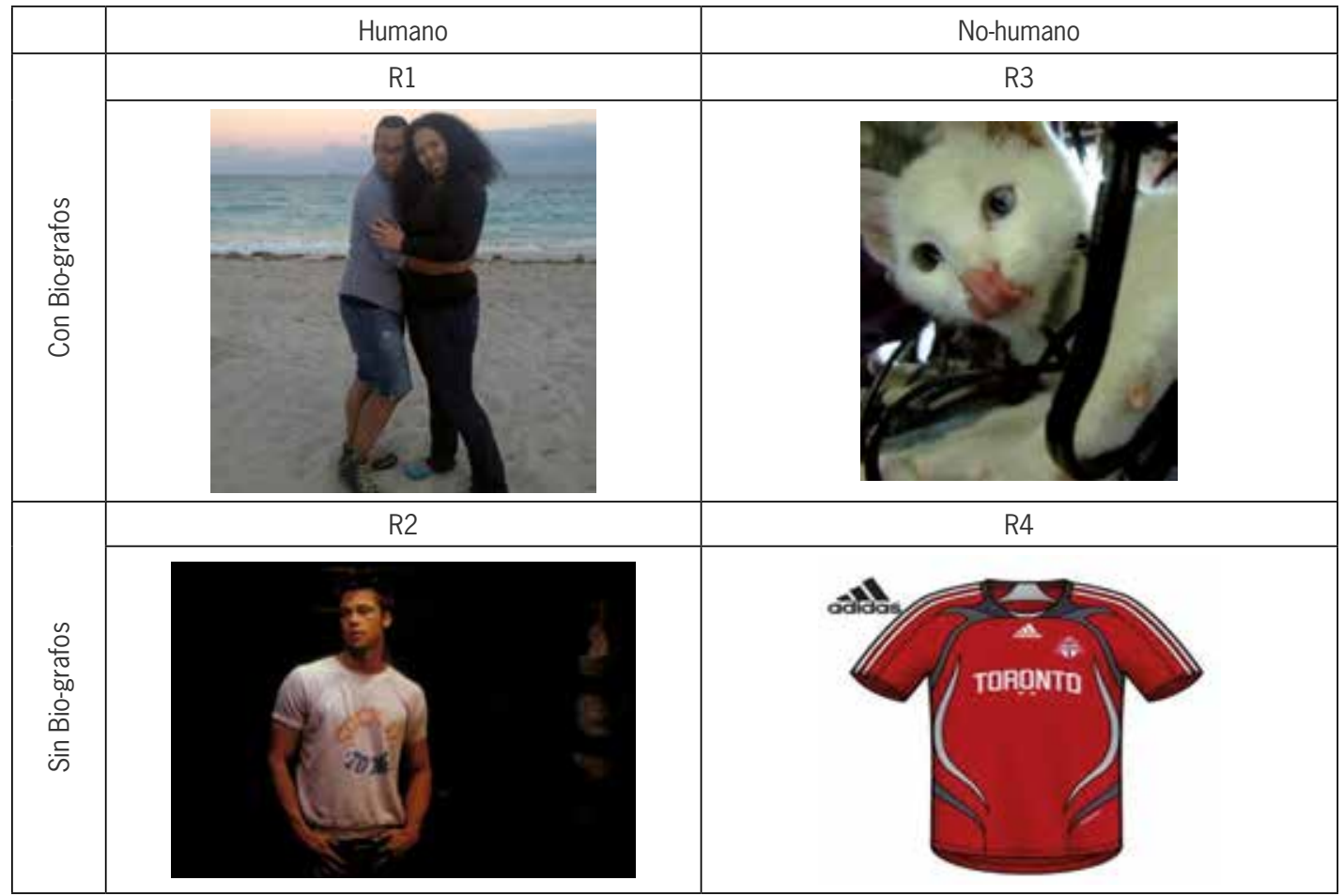

R1: Humano con bio-grafos, R2: Humano sin bio-grafos, R3: No-humano con bio-grafos, R4: No-humano sin bio-grafos.

Tabla 2. Tipos de tratamiento

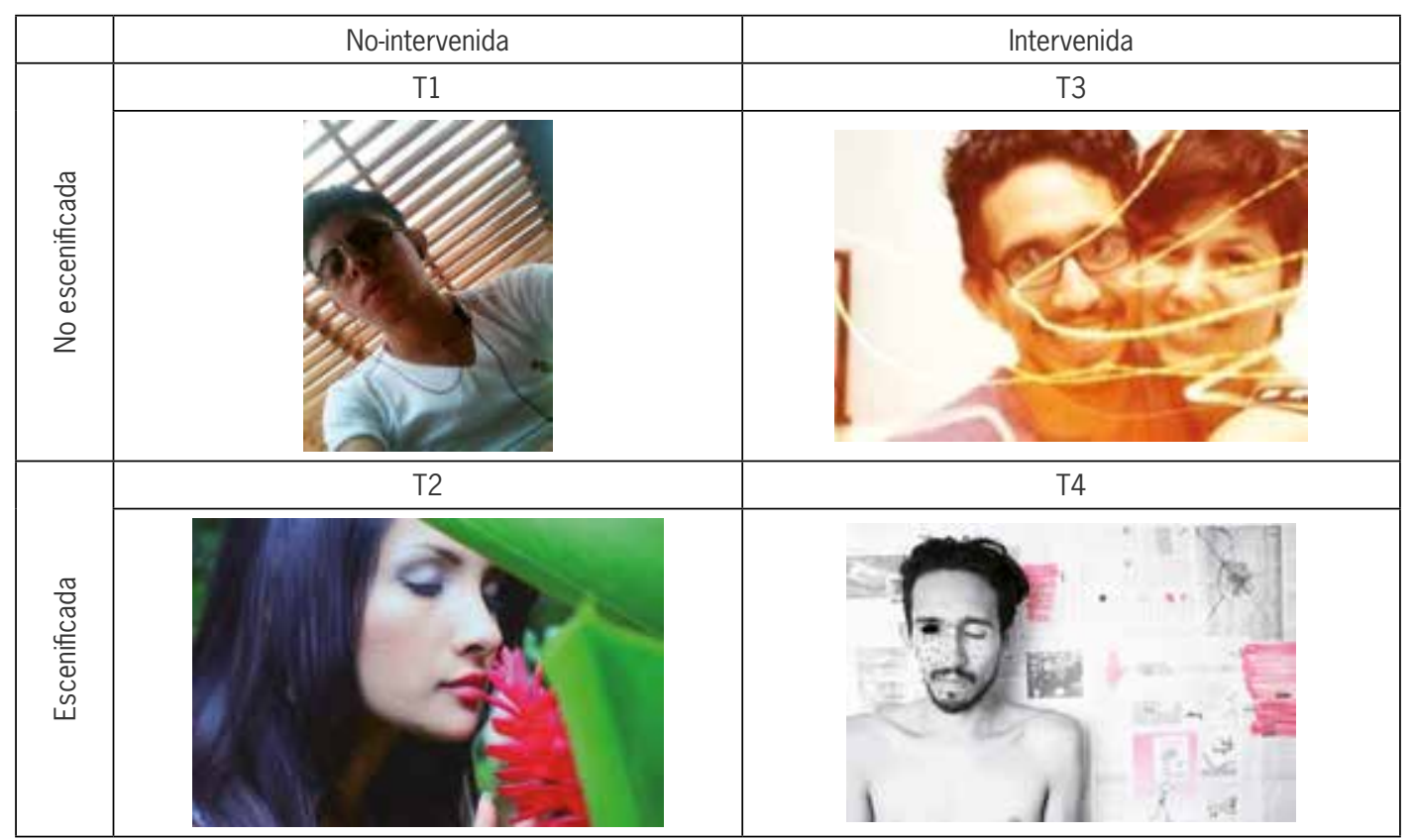

T1: No-intervenida y no escenificada, T2: No-intervenida y escenificada, T3: Intervenida y no escenificada, T4: Intervenida y escenificada. 
Encuadramiento (E) se refiere a la cantidad de información que provee la imagen. Aquí, la primera variable indica qué tanto se muestra la entidad representada: una unidad completa reconocible o solo una porción de esta. La segunda variable se orienta al contexto. Es amplio cuando hay información reconocible del contexto de vida del propietario del perfil, o limitado, si hay muy poca o ninguna información de este. La tabla 3 ilustra las cuatro formas posibles de encuadramiento.

Tabla 3. Tipos de encuadramiento

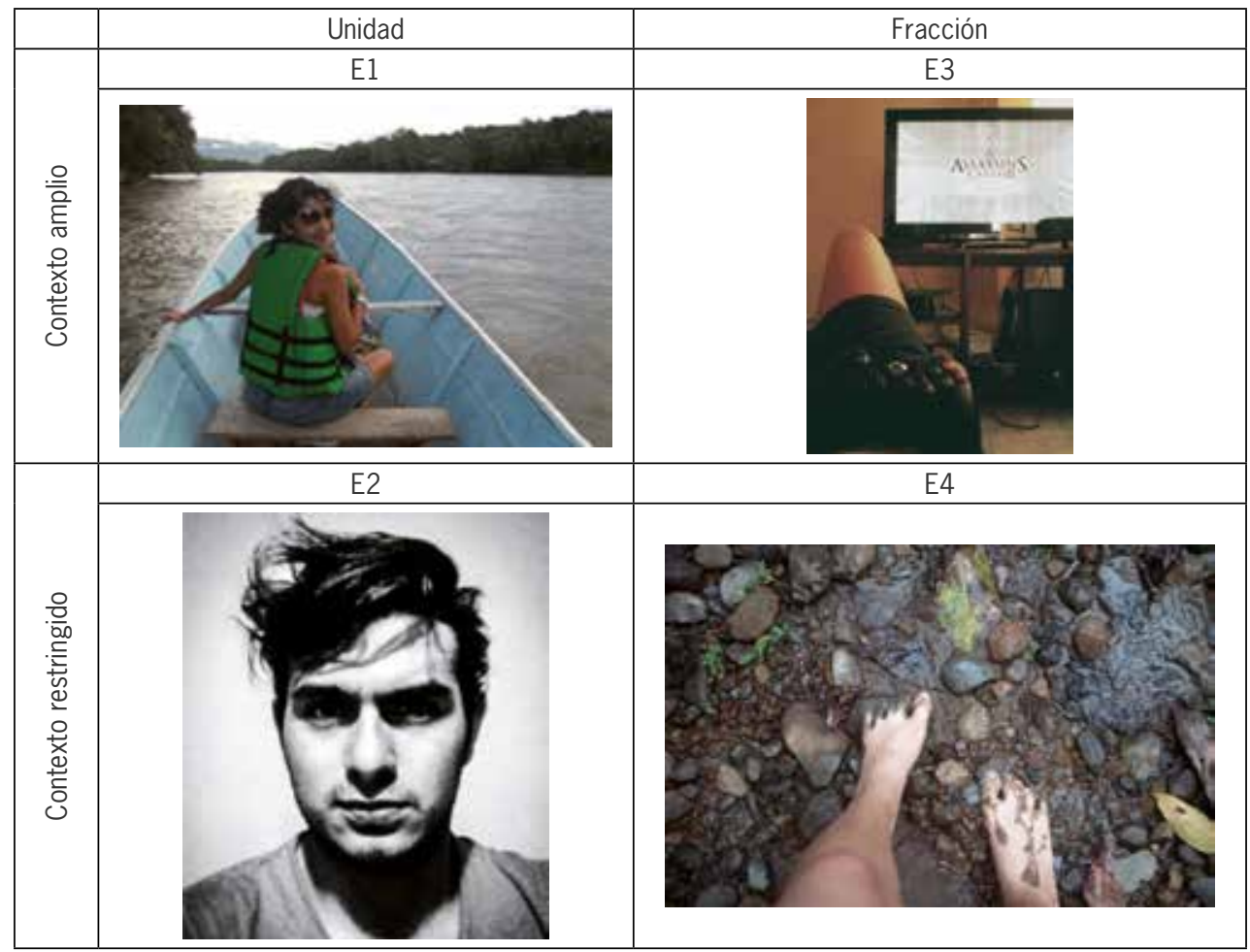

E1: Unidad con contexto amplio, E2: Unidad con contexto limitado, E3: Fracción con contexto amplio, E4: Fracción con contexto limitado.

Finalmente, el modelo RTE hace posible la creación de 64 configuraciones que resultan del análisis combinatorio de las tres categorías, como se muestra en la tabla 4.

Tabla 4. Configuraciones

\begin{tabular}{|l|l|l|l|l|l|l|c|}
\hline R1T1E1 & R1T3E1 & R2T1E1 & R2T3E1 & R3T1E1 & R3T3E1 & R4T1E1 & R4T3E1 \\
\hline R1T1E2 & R1T3E2 & R2T1E2 & R2T3E2 & R3T1E2 & R3T3E2 & R4T1E2 & R4T3E2 \\
\hline R1T1E3 & R1T3E3 & R2T1E3 & R2T3E3 & R3T1E3 & R3T3E3 & R4T1E3 & R4T3E3 \\
\hline R1T1E4 & R1T3E4 & R2T1E4 & R2T3E4 & R3T1E4 & R3T3E4 & R4T1E4 & R4T3E4 \\
\hline R1T2E1 & R1T4E1 & R2T2E1 & R2T4E1 & R3T2E1 & R3T4E1 & R4T2E1 & R4T4E1 \\
\hline R1T2E2 & R1T4E2 & R2T2E2 & R2T4E2 & R3T2E2 & R3T4E2 & R4T2E2 & R4T4E2 \\
\hline R1T2E3 & R1T4E3 & R2T2E3 & R2T4E3 & R3T2E3 & R3T4E3 & R4T2E3 & R4T4E3 \\
\hline R1T2E4 & R1T4E4 & R2T2E4 & R2T4E4 & R3T2E4 & R3T4E4 & R4T2E4 & R4T4E4 \\
\hline
\end{tabular}


Al final del proceso de clasificación se creó un catálogo por cada ciudad. Los catálogos fueron realizados por diferentes miembros del equipo de investigación. Sin embargo, intentamos eliminar la subjetividad en muchos encuentros de verificación y discusión de los resultados.

\section{Segunda fase: trabajo de campo etnográfico}

Esta segunda fase se desarrolló entre mayo y octubre de 2012 y consistió en la realización de entrevistas a 12 personas usuarias de Facebook y en la observación de su actividad en dicha plataforma. Nuestro propósito fue identificar qué formas de representación se mantienen y qué otras han cambiado respecto a la práctica fotográfica en la vida cotidiana.

La selección de este grupo se basó, fundamentalmente, en que sus páginas de Facebook estuvieran abiertas al público, que mostraran una actividad alta en el mantenimiento de la misma y sobretodo, que nos autorizaran a realizar la observación de sus Facebook durante 6 meses y estuvieran dispuestos a participar en entrevistas. Este seguimiento se apoyó en una guía de observación semanal y de fines de semana y en la realización de entrevistas quincenales (presenciales o vía videoconferencia). En dichas entrevistas, conversamos sobre los registros e intentamos aclarar los sentidos de la actividad en Facebook durante dicho periodo de tiempo. El grupo de sujetos (12 personas) quedó conformado por 5 mujeres y 7 hombres, distribuidos así: 8, están entre los 20 y los 30 años de edad ( 4 mujeres y 4 hombres, el grupo más joven del estudio); 2, hombres entre los 30 y 50 (conforman el grupo de adultos) y 1 de 70 años (una mujer adulto mayor). En consecuencia, la mayoría de personas del grupo (8 personas) pertenecen a una generación joven "universitaria" de clase media de la ciudad de Cali. Por último, los dos adultos hombres están dedicados a sus trabajos profesionales (en la comunicación y el turismo) y la adulta mayor está actualmente pensionada. En el presente texto solo daremos cuenta de los resultados en relación con la imagen de perfil, sin embargo, como producto de este trabajo etnográfico se observaron otros elementos que tienen que ver con los mundos de la vida de los sujetos, las maneras en que se construyen las obras o artesanías mundanas y también la emergencia de formas de poetización de la experiencia de sí a través de las obras.

\section{Principales resultados y discusión}

\section{Primera fase}

El inventario de imágenes tuvo un carácter fundamentalmente exploratorio. Nuestro objetivo fue poner a prueba el modelo de clasificación de las imágenes (RTE), descrito antes, e identificar, a pesar de las diferencias culturales y sociales entre las ciudades, lo que aparecía como regularidad en las imágenes de perfil de Facebook. Advertimos que no fue nuestra intención realizar un análisis intercultural sobre estas imágenes. Para ello se requeriría acudir a otras técnicas de recolección de información cualitativa en cada una de las ciudades seleccionadas. En consecuencia, a continuación presentamos los resultados generales, a partir de las regularidades encontradas con base en 7200 imágenes de perfil analizadas.

\section{El canon de la imagen de perfil en Facebook y los otros 3 tipos de imágenes}

Uno de los hallazgos más interesantes de nuestra investigación es lo que hemos llamado "el canon de la imagen de Facebook", es decir, la típica imagen de perfil: la configuración R1T1E1 (humano con bio-grafos, no intervenida, no escenificada y unidad con contexto amplio). Como se puede observar en el gráfico 1, de los 24 catálogos de las ciudades seleccionadas, 19 tuvieron más de 200 imágenes en este tipo de imagen canon (de las 300 imágenes en cada catálogo). Incluso, en los cinco catálogos con la menor cantidad de imágenes prototipo, la mitad de las fotos pertenecen a este canon.

Al combinar el tipo representante con el tratamiento, encontramos una alta concentración de representaciones con bio-grafos y una clase de tratamiento natural de las imágenes, es decir, estas no son ni modificadas ni escenificadas teatralmente. Así, el $83 \%$ del total de las imágenes eran fotografías 
naturales y espontáneas, 97,44\% describen unidades completas (no porciones de los cuerpos, o rostros u objetos) que no son ni fraccionadas, ni modificadas, ni escenificadas. Encontramos que el $90 \%$ de las imágenes de perfil tienen figuras humanas: solamente el $10 \%$ son entidades no humanas, como animales, objetos o paisajes. Más de la mitad de las imágenes ( $54 \%$ ) muestra cuerpos no intervenidos o escenificados y los rostros revelan porciones significativas del mundo cotidiano de los sujetos.
Estos hallazgos nos muestran una fuerte tendencia al mantenimiento de las formas heredadas de los modos de presentación cara a cara, del mundo off line y el interés de dar cuenta del mundo biográfico. A pesar de las affordances técnicas de las cámaras de fotos y de los programas de edición fotográfica y diseño gráfico en Internet, una gran cantidad de las imágenes que se suben a los perfiles no tienen un tratamiento técnico visual previo o posterior.

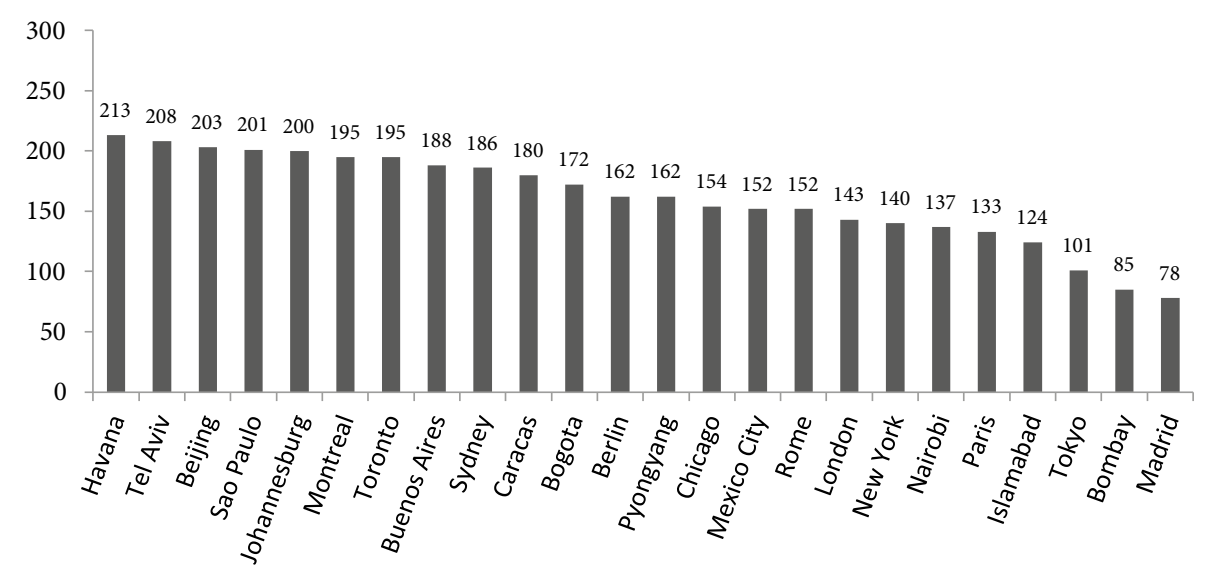

Gráfico 1. Frecuencias R1T1E1

\section{Tipo R2: Humano sin bio-grafos}

En este tipo se encuentran muy pocas imágenes (gráfico 2). Solo en 5 catálogos se registraron entre 62 y 138 imágenes. En 19 catálogos, la presencia de estas imágenes es inferior a 50 fotos de las 300 que cada catálogo contiene. Aquí, es llamativa la ausen- cia del mundo cotidiano de los sujetos, y en cambio es alta la presencia de sujetos de la iconografía de los medios y las industrias culturales (celebridades de cine y televisión, periodistas, deportistas, músicos, y personajes de la industria de videojuegos) así como figuras religiosas (Buda, Cristo).

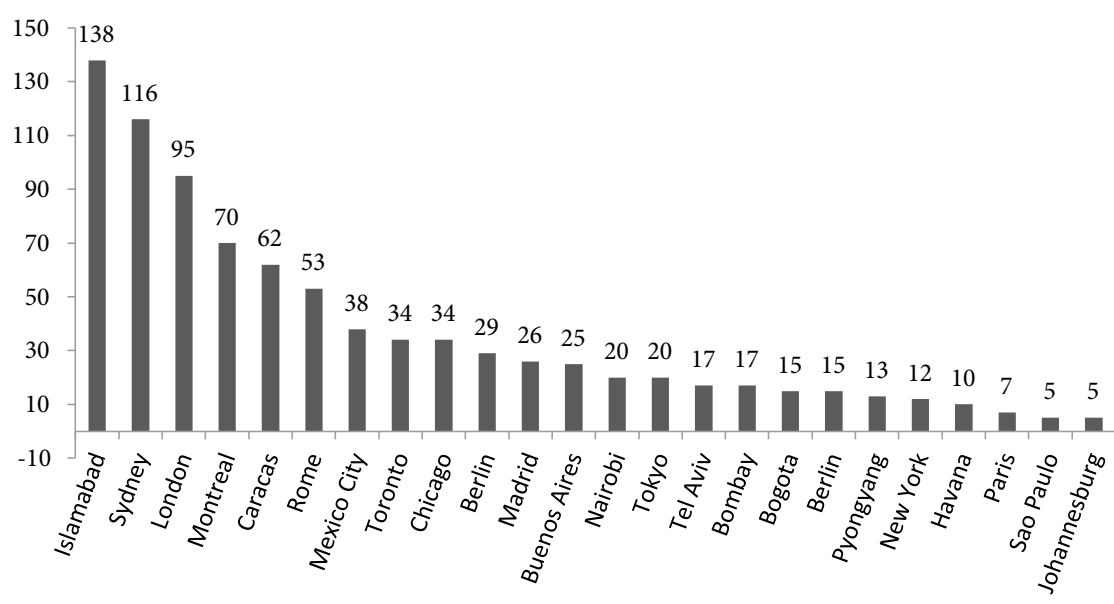

Gráfico 2. Frecuencias R2: Humano sin bio-grafos 


\section{Tipo R3: No humano con bio-grafos}

El tipo no humano con bio-grafos es el menos frecuente (gráfica 3). De las 300 imágenes disponibles por catálogo, se encontraron máximo entre 12 y 19 imágenes. De hecho, en 3 ciudades no existe ninguna imagen de este tipo. $\mathrm{Al}$ menos en los casos que analizamos, parece no ser común el uso de no humanos con información biográfica (mascotas, objetos, paisajes) como imágenes de perfil.

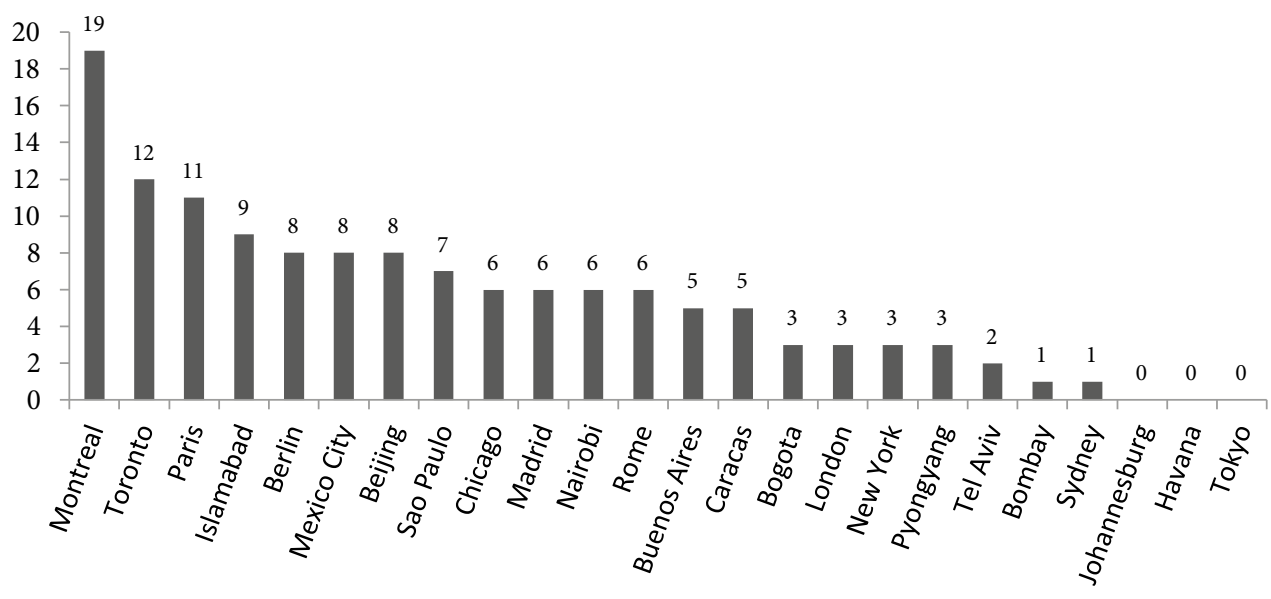

Gráfico 3. Frecuencias R3: No humano con bio-grafo

\section{Tipo R4: No humanos sin bio-grafos}

Este tipo de imagen, aunque es poco frecuente (gráfica 4), tiene mayor número de reporte de casos que el tipo no humano con bio-grafos. El caso con mayor número de imágenes de este tipo tuvo 61 imágenes, seguido por 51 y 45 . El caso mínimo reportó una imagen. En este tipo de imágenes al parecer es mucho más probable que los sujetos prefieran acudir a imágenes de las industrias culturales, o de Internet, sin presentar rastros de su vida cotidiana. Sin embargo, estas imágenes también tienen fuerza simbólica comunicativa sobre los mundos de la vida de los sujetos en relación a intereses y estilos de vida (deportes, música, artistas del cine y la televisión, religión, etc.). Tanto en el tipo 3 como en el tipo 4 la información biográfica está asociada con representaciones humanas.

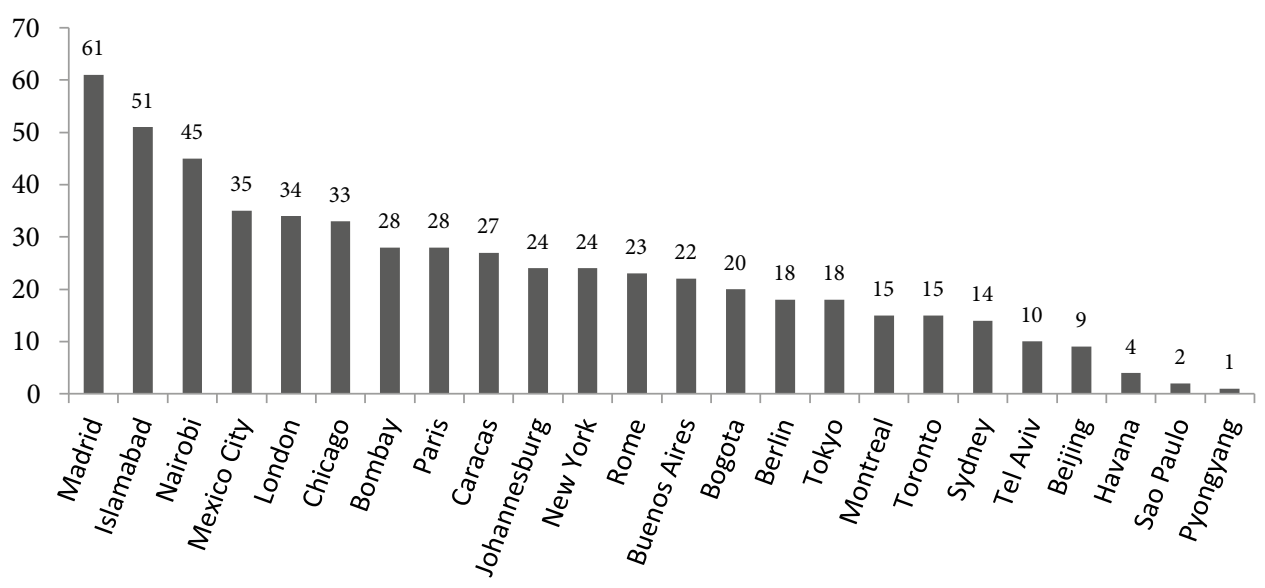

Gráfico 4. Frecuencias R4: No humano sin bio-grafos 
Adicionalmente, en estos dos últimos tipos de imágenes, es relevante destacar que el $11 \%$ de las imágenes que representan cuerpos y rostros son generadas en el mundo digital a través de las industrias culturales y de medios con un contexto limitado y aparentemente libre de intervención o escenificación. En cualquier lugar donde una imagen del tipo humano sin bio-grafos es usada, el sujeto llena la unidad del marco, sin mostrar huellas del ambiente o contexto. Este es un uso extremo de la fachada, en términos de Goffman. Usar imágenes de personalidades ampliamente conocidas en los medios e industrias culturales parece ser una clase de idealización de la fachada, porque ellos expresan jerarquías y valores sociales aceptados, y en consecuencia reciben también mayor recepción y consenso (lo cual es muy importante especialmente para los jóvenes). Por otro lado, la combinación no humano con bio-grafos es muy rara; esta es muchas veces una imagen tomada del mundo digital sin ninguna relación con el contexto del usuario y publicada en Facebook como la imagen de perfil.

De acuerdo con los datos recogidos, destacamos que la tendencia o canon de las imágenes en Facebook es el tipo I: humano, con bio-grafos, no intervenida, no escenificada. Los bajos niveles de exploración gráfica digital aun en ciudades como New York, Londres o Buenos Aires, con un alto nivel de uso de tecnologías, nos lleva a creer en la presencia de viejas formas de auto-representación en la actualidad. Por lo tanto, no es posible generalizar el carácter novedoso de la presentación de sí en Facebook. Sin embargo, y aunque en una tendencia menor, observamos en los usuarios más jóvenes una mayor interacción con las affordances técnicas que la red social ofrece, así como con los de otros dispositivos técnicos que tienen a su alcance. De hecho, cuando se observan los perfiles de personas adultas y de jóvenes, se observan diferencias. Mientras las personas mayores tienden a usar imágenes sin mayor tratamiento, encuadramiento y escenificación, los más jóvenes parecen explorar con mayor intensidad las posibilidades que ofrece la red social. Así, una mayor exploración de las posibilidades técnicas parece relacionarse también con una intensa exploración de los procesos de identificación juvenil. En las personas adultas, aspectos de identificación y de construcción del universo social no están en primer plano, sino intencionalidades comunicativas y de mantenimiento y cuidado del vínculo con personas pertenecientes a la familia y el círculo de amigos.

En suma, las imágenes en Facebook nos muestran tres tendencias: primero, la gente parece asumir que algo (humano/no humano) debe estar presente; una entidad que contenga las cualidades necesarias para que los usuarios se identifiquen y presenten a sí mismos, principalmente los que pertenecen al tipo humano con bio-grafos (el canon). Así, frente a la hipocresía y el engaño que muchas personas temen del mundo virtual, encontramos que la mayoría de los usuarios publican imágenes de su vida actual. En algunos casos, tendencias espirituales y religiosas ejercen gran influencia en la selección de la imagen, por ejemplo; en otros, las personas reemplazan el auto-retrato con una imagen de una personalidad de los medios y las industrias culturales o un ícono religioso.

Segundo, como se mencionó antes, estas entidades tienden a exhibir cierta completitud (rostros o cuerpos completos), generando así un gran número de imágenes con contexto amplio. Experimentar con la imagen de perfil, fraccionándola, focalizando un detalle, o realizando un acercamiento extremo, dificulta el reconocimiento de esas entidades (imágenes de perfil). Sin embargo, incluso una fracción de un rostro o cuerpo humano logra presentar algunos elementos que permiten identificar y reconocer al sujeto, una posibilidad que parece que se pierde cuando se acude a objetos inanimados o no humanos.

Tercero, aunque la intervención de las imágenes es ocasional, esta sucede principalmente en las imágenes del tipo humano con bio-grafos, mientras los objetos no humanos son muy rara vez modificados. La escenificación de la imagen también es poco frecuente tanto en el tipo de representante humano como no humano. No obstante, tanto los usuarios que solamente suben y clasifican tomas espontáneas sin un tratamiento posterior como aquellos que experimentan visualmente con su imagen nos están mostrando una gama de posibles obras y formas de artesanía de la autoimagen $y$, en consecuencia, nuevas posibilidades 
de exploración identitaria. Sennett (2009) de hecho propone que la imitación, la atención en los detalles, junto a la apropiación de los secretos de otros para usarlos en el propio trabajo, son habilidades muy valiosas que deberían ser valoradas como parte de los procesos de construcción de la singularidad como artesanía de nuestra propia vida.

Así, la imagen de perfil como opera es producida en algunas ocasiones a través de un objeto de experimentación artística y, en otras, al encontrar los recursos apropiados (el preciso tiempo, las personas, la escena requerida). Pero en muchos otros casos, esto ocurre en el proceso de exploración identitaria durante las interacciones en el día a día (off y on line) y en su captura a través de tecnologías de la imagen. Así, la cotidianidad y las tecnologías están mutuamente constituidas a través de un proceso continuo de artesanía. De acuerdo con Sennett (2009), mientras estamos trabajando, hay procesos de pensamiento y sentimientos que se producen simultáneamente. Casi sin ser conscientes de ello, nos orientamos a los más altos estándares que nos exigen las cualidades de nuestro trabajo, o nuestra opera.

A continuación, señalamos dos tendencias notables sobre la gramática de las imágenes, en cuanto al tratamiento y encuadramiento y lo que ellas nos permiten ver sobre las permanencias y transformaciones en las formas de presentación de sí.

\section{Tratamiento y encuadre:10 captura} del momento, posar y publicar

En el caso de los sujetos que realizan un tratamiento y/o un encuadramiento de sus imágenes a través de

10 Terminada la investigación nos han dado una retroalimentación muy interesante sobre cómo el término "encuadre" $y$ "encuadramiento" podría asimilarse al de composición. No obstante, esta discusión no la hicimos en este estudio. Acudimos a encuadre fundamentalmente como un término técnico que implica "límites del cuadro", "captura del momento", no composición (ordenamiento de los elementos dentro del cuadro), y una subjetividad que no conocíamos. Esto nos permitió construir el modelo de formalización de las formas de presentación de las páginas de Facebook que revisamos. El término "composición" desde la teoría de la fotografía y la teoría de la iconografía por su capacidad de activar analogías, aportaría mucho más a comprender asuntos del sentido y las relaciones que crean los objetos que se hallan en el marco. Desde aquí, sin duda, se abren nuevas ventanas de comprensión de este fenómeno de la presentación de sí en las redes sociales digitales. procedimientos de pre y posproducción, el proceso difiere de la fotografía tradicional, es decir, una fotografía en un estudio o tomada en ocasiones familiares especiales. Debido a la capacidad de las nuevas tecnologías para multiplicar las posibilidades de grabación de todo tipo de acontecimientos de la vida cotidiana, "la captura del momento" es la práctica más extendida. La existencia de varios dispositivos de captura de imágenes parece fusionar el evento con su registro visual. "Estar en un lugar" es una ocasión suficiente para tomar fotos, lo que genera, en términos de Fontcuberta (2010), "imágenes Kleenex: para usar y tirar". Al mismo tiempo, notamos que la experiencia del mundo se convierte en una ocasión para posar. Un amplio espectro de códigos de relación, como Barthes (1989) señaló, puede ser observado en fotos compartidas por jóvenes; desde un simple gesto saludatorio hasta expresiones más sofisticadas relacionadas con el afecto, la simpatía, la cordialidad, la seducción. Así, publicar, enviar y compartir fotos funciona como un nuevo sistema de comunicación.

\section{Efectos visuales y retro-estética}

En el tipo humano con bio-grafos, intervenido, se requiere un trabajo de posproducción en la imagen digitalizada, para lo cual es común encontrar toda clase de "retoques". La gente joven, de hecho, puede jugar y experimentar con su imagen usando diferentes herramientas para la edición como Photoshop y otros ${ }^{11}$. También encontramos una fuerte tendencia a usar imágenes en blanco y negro, en la cual la experimentación con la escala de grises produce interesantes texturas a nuestros ojos saturados de color. La tendencia (observada en todos los catálogos) podría indicar un regreso a una retroestética que parecía haberse convertido en obsoleta con la llegada de las actuales tecnologías de la imagen. Tal vez, la apariencia de lo viejo y gastado puede producir ahora novedad en la comunicación visual moderna.

11 PhotoScape y otras herramientas en línea para el retoque de imágenes como PinkMirror, entre otros. 


\section{Segunda fase}

En la segunda fase, nuestro propósito fue identificar las formas de representación que permanecen y las que han emergido en relación con la práctica fotográfica en la cotidianidad. Aquí, consideramos que la imagen de perfil debería ser estudiada en relación, no solamente con viejas y nuevas tecnologías, sino, sobre todo, en relación con la representación de lo que la tecnología puede hacer (Van Dijck, 2008). En este sentido, afirmamos que aunque la publicación de una imagen personal en Facebook depende de las restricciones y posibilidades de la plataforma, la creación depende del mundo simbólico del usuario. Es por ello que en esta segunda fase de la investigación nos apoyamos tanto en la etnografía virtual como en entrevistas, para aproximarnos a dicho universo simbólico. A partir de las entrevistas, pudimos identificar algunos de los cambios y continuidades de las prácticas fotográficas y cómo nuestros usuarios-artistas, además de la habilidad para representar y preservar la memoria, también confieren a las imágenes una función narrativa, performativa, política o relacional. Así, observamos que mientras algunas prácticas aún continúan, otros valores diferentes surgen acerca de lo que las imágenes muestran, el dónde, cuándo, con quién.

En las entrevistas, los participantes revelaron fuertes conexiones con la fotografía desde la infancia y tienen recuerdos claros acerca de esto: álbumes familiares, la primera cámara y su uso para documentar y grabar viajes, fechas especiales y eventos biográficos significativos. Esto lo vemos también en Facebook. Muchos de nuestros entrevistados consideran a Facebook como un lugar para la memoria $\mathrm{y}$ archivo de sus fotos tal y como lo hicieron antes con sus álbumes familiares. Pero este es solo uno de los muchos usos posibles de Facebook. La función representacional coexiste con las nuevas prácticas en las cuales las imágenes son consideradas como recursos visuales para hacer y decir algo más.

Almacenar fotos en Facebook hace posible exhibir imágenes de una manera permanente y continua. Dependiendo de sus intereses, los usuarios toman ventaja de esta cualidad técnica para crear un diálogo con amigos y otras personas de esta red social. Visto como un diario personal, Facebook es un repositorio de estados de ánimo y sentimientos. Visto como una galería de imágenes, Facebook es un lugar para exhibir sus trabajos visuales. Visto como un blog, Facebook es un lugar para publicar contenidos, generar discusiones, participar en activismo ciudadano. Esta multiplicidad de usos revela una transformación de los procesos identitarios, un constante trabajo de creación y de re-creación de uno mismo en el cual los individuos hoy, con el potencial de las redes sociales y la fotografía digital, se hacen responsables de construir el proyecto de sí mismos (Giddens, 1991), entre una variedad de opciones.

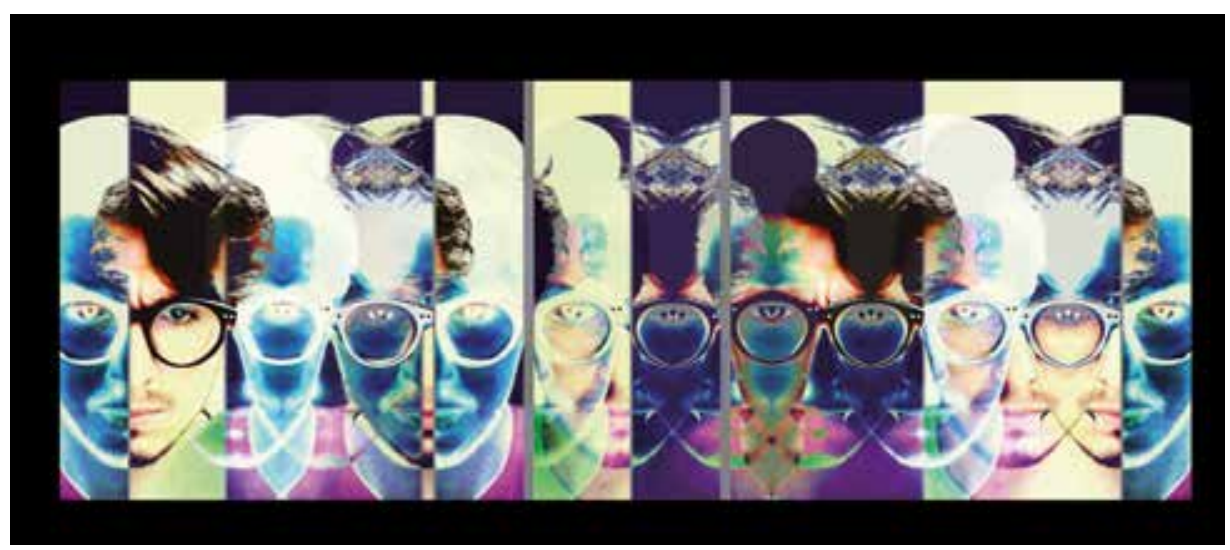

Imagen 1. Realizada por uno de los participantes en el estudio ${ }^{12}$

12 Publicada con su autorización 
También encontramos que la experimentación gráfica es mucho más frecuente en los álbumes que en la imagen de perfil. Dado que esta imagen, tal y como es concebida por Facebook, sirve para identificar a los usuarios dentro de la red, los usuarios deben ponderar sus necesidades de presentación y reconocimiento, frente a los intentos de experimentación expresiva de su propia imagen. La gran tendencia que encontramos en la foto de perfil es el uso de una imagen que acude a la representación en su sentido moderno, es decir, como una unidad de sentido y visión auténtica del mundo. La experimentación, en consecuencia, puede desenfocar o amenazar la identificación del sujeto. Los álbumes proponen por su parte una opción que permite la experimentación y la representación a través de la narración visual; muchos usuarios crean álbumes temáticos de diferentes clases, algunos con propósitos de experimentación visual claros, mientras otros tienen más un carácter documental, de registro de tópicos de interés sin un tratamiento posterior. En ambos casos, los álbumes contienen referencias cruzadas con otros sujetos (a través de tags, comentarios, títulos), lo que refuerza los lazos en las redes sociales.

Respecto a la presentación pública de la persona, una transición parece estar tomando lugar: desde los orígenes de la fotografía moderna como una representación mimética, realista y una representación estática del sujeto, localmente situada, a una multiplicación de los dispositivos de fotografiar así como de los tiempos y espacios para re-presentarse, tal como lo describen Barthes (1989) y Benjamin (1973). Se trata de una construcción subjetiva a través de un contexto dinámico semipúblico de intenso intercambio simbólico. Sin embargo, los arquetipos culturales de la interacción cara a cara son reproducidos y mantenidos en los ambientes tecnológicos porque la evolución tecnológica no es igual a evolución cultural; en consecuencia, los usuarios prefieren reglas de representación convencionales (fotos sin tratamiento ni escenificación) que no amenacen su reconocimiento y aceptación dentro de la red. Pero, al mismo tiempo, y aunque en menor cantidad, también se observa que muchos jóvenes - como ocurre en la interacción cara a cara- tienen la necesidad de experimentar con su propia autoimagen más allá de las reglas establecidas, escenificando y modificando su imagen, que luego será publicada principalmente en los álbumes digitales que posibilita la plataforma.

En ese sentido, la imagen de sí en Facebook funciona como un símbolo que permite, especialmente a las generaciones jóvenes, compartir con las redes familiares y de amigos, un mundo significativo. Así, a través de una cierta nueva forma común de presentarse, donde se comparten pensamientos, sentimientos, actitudes y valores, se aprende a interpretar la propia imagen y la de otros. El punto crucial aquí es que este proceso siempre se está llevando a cabo en relación con las reacciones de los otros, que pueden ver e interpretar las acciones del yo. En Facebook, este proceso se hace mucho más intensivo y reflexivo cuando las acciones de nuestra presentación pública se traducen en obras que permanecen, como el lenguaje escrito, para ser leídas una y otra vez por otros. De ahí que el proceso de presentación de sí se haga mucho más complejo y más difícil de controlar que como sucede en la interacción cara a cara.

\section{Conclusiones}

Como lo señalaron Gómez y González (2012), registrar o publicar una imagen de perfil es el último de una serie de procedimientos que involucran decisiones emocionales, cálculos y estrategias de diverso tipo, tomar la imagen, revisar el archivo como la habilidad para subir y bajar archivos de fotos, etc. Este es un ritual digital de paso, el cual celebra la presencia y la exposición del sujeto en la red social. Así, la imagen de Facebook es la convergencia de un ecosistema comunicativo ofrecido por la plataforma y un conjunto de decisiones y procedimientos, que parecen culminar con "subir" la imagen a Facebook, pero que continúan con la transformación y enriquecimiento a través de las interacciones que ocurren alrededor de este; en definitiva un proceso de reflexividad permanente. Los hallazgos sobre la imagen tipo "canon" podrían estarnos mostrando más una intensa exploración social que una exploración técnica de todo el ambiente comunicativo que ofrece 
Facebook. Sin embargo, dado que el espacio para la imagen de perfil no ofrece herramientas para el tratamiento de la misma, esta puede ser una condición que se constituye en una restricción técnica de dicho entorno. Así, quienes realizan mayor tratamiento de la imagen deben acudir a otros dispositivos y espacios de edición de la misma, es decir, por fuera de la plataforma Facebook.

Igualmente, encontramos que existe una línea borrosa entre el escenario y el detrás de bastidores o backstage: lo que parece un espacio íntimo para y con los amigos puede estar abierto a la mirada digital de una audiencia grande y desconocida. Lo que está siendo actuado en el escenario podría no tener testigos. En términos de intercambios en línea en las redes sociales, puede argumentarse, como otros investigadores lo han destacado (Di Prospero, 2011), que la actuación es una mezcla de atributos de lo privado y lo público, un escenario inserto dentro de espacios privados que contienen relaciones personales y a veces íntimas. Sin embargo, también está abierto a personas externas. Así, la performatividad en las redes sociales como Facebook enfatiza la yuxtaposición entre lo privado y lo público.

Tal y como Goffman propuso en relación al contacto interpersonal cara a cara, vemos que los usuarios de los espacios en línea, asumen roles usando códigos y signos desarrollados y aprendidos a través de la interacción off y on line. Al hacer esto, la mayoría del tiempo los sujetos son conscientes (en mayor o menor medida) de otros usuarios, como la audiencia de amigos, navegantes de la web, y otro amplio público de las redes sociales. En cualquier caso, la posibilidad de revisar permanentemente el perfil, tomar una nueva foto, actualizarla, retocarla, todo esto enmarcado en un intenso diálogo con los "amigos", produce un ambiente de reflexividad sobre la presentación de sí mismo como una obra (opus). La fuerte tendencia hacia uno o dos tipos de configuración y la poca presencia de casos que escapan a los modos de representación tradicional o heredados, confirman la idea de Goffman en la cual la presentación de sí es un proceso dialéctico. De hecho, Facebook no es simplemente el "libro de los rostros", ni un entorno de simple consumo superficial. Por el contrario, publicar una imagen propia, o la imagen de una celebridad, de una mascota, o de una camiseta del equipo de fútbol favorito, etc., no es un acto aleatorio: ¿quién puede ver esta imagen y quién puede entenderla?, ¿qué interpretaciones se hacen de esta?, son algunas cuestiones en las que es necesario profundizar para comprender el cambio cultural.

Aunque los críticos han argumentado que Goffman tiende a sobrevalorar la importancia de las reglas y a negar aspectos como la improvisación, o el hábito de animarnos que caracteriza la vida cotidiana, consideramos que su planteamiento sigue siendo útil para el entendimiento de los usos de los medios digitales. Para nosotras, la experiencia subjetiva en Facebook no está predeterminada sino que está unida a un conjunto de reglas, protocolos y condiciones de interacción y comunicación ofrecidos por el nuevo ambiente tecnológico. Por ejemplo, encontramos que alrededor de la imagen de perfil, se debe leer el conjunto de las piezas comunicativas que integran la página: las imágenes, los textos, los símbolos usados como escenario, la apariencia, las reglas y roles de interacción que se esperan desempeñar en la plataforma, como las reglas de etiqueta que son muy importantes. La actuación es también relevante. Así, Facebook ha sido adaptado y reajustado por marcos sociales donde la experiencia individual y colectiva toma lugar.

Sin embargo, el estudio de la imagen de perfil en Facebook nos llevó a considerar un nuevo aspecto que no estaba inicialmente incluido en la perspectiva goffmaniana: la perdurabilidad de la imagen de perfil - aunque sea inmaterial, digital-. A diferencia de la actuación en la interacción cara a cara, la imagen de perfil en Facebook ofrece en sí misma pre y posproducciones y deja huellas digitales, las cuales son almacenadas en dicha red social. Esto significa que la imagen es mantenida a lo largo del tiempo. Las huellas permanecen y pueden ser vistas en diferentes momentos y por diversas personas. Así, la imagen de perfil tiene dos funciones sociales: por una parte, el proceso de explorar y ajustar las 
maneras de autorrepresentación por el actor-autor y los observadores. Por otra parte, esta facilita establecer y mantener lazos sociales con otras personas y desempeñar un rol importante en la definición de reglas para la autoimagen en la red social, así como en la recreación y enriquecimiento de la experiencia diaria.

Volviendo a uno de los puntos iniciales, quizás la cuestión más importante es que la identidad y la auto(re)presentación puede ser analizada en el mismo soporte en el cual está siendo desplegada. Sin embargo, un entendimiento mucho más profundo del rol de las tecnologías digitales en nuestras vidas requiere de una aproximación no determinista. Muchas veces, una de las primeras maneras en las cuales la gente se relaciona frente a las nuevas tecnologías es tratando de hacer lo que ya es habitual en otras, antes de empezar a experimentar nuevos usos. Así, mientras viejas prácticas pueden estar siendo redefinidas y hasta desplazadas, ellas también coexisten con las nuevas. Por lo tanto, es importante no solo mirar los cambios en la fotografía como una práctica cotidiana, sino también las continuidades. Si consideramos Facebook como un ambiente real de creación, en lugar de asumirlo como una simple herramienta para almacenar fotos, podríamos entender a cabalidad su rol constitutivo en la construcción de significado en la vida cotidiana. Por tanto, creemos que la vida diaria y las prácticas cotidianas son los contextos donde se insertan las tecnologías y no al contrario. Consideramos que la integración de las tecnologías digitales en nuestras rutinas diarias es más el resultado de la evolución, ajuste y negociación entre nuestras tradiciones heredadas y el deseo de transformar nuestras sociedades en lugar de una revolución o una ruptura radical.

\section{Referencias}

Barthes, R. (1989). La cámara lúcida. Notas sobre la fotografía. Barcelona: Paidós.

Benjamin, W. (1973). La obra de arte en la época de su reproductibilidad técnica. Madrid: Taurus.
Buckingham, D. (2008). Introducing identity. En D. Buckingham (Ed.), Youth, identity, and digital media (pp. 1-24). Cambridge, MA: The MIT Press.

Di Prospero, C. (2011). Autopresentación en Facebook: un yo para el público. Revista Latinoamericana de Estudios sobre Cuerpos, Emociones y Sociedad, 6 (3), 44-53.

Cardon, D. (2008). Le design de la visibilité : Un essai de cartographie du web 2.0. Réseaux, 152, 93-137.

Fontcuberta, J. (2010). La cámara de pandora. La fotografí@ después de la fotografía. Barcelona: Gustavo Gilli.

Giddens, A. (1991). The consequences of Modernity. Cambridge: Polity Press.

Goffman, E. (1959). Presentation of self in everyday life. New York: Doubleday Anchor.

Gómez, R., y González, J. (2009). Formas de presentación pública de la persona en Facebook. Nexus 8, 54-65

Gómez, R., y González, J. (2012). Rutas y configuraciones de la imagen de perfil en Facebook. Documento interno de trabajo. Universidad del Valle, Cali.

Gómez, R., y González, J. (2013). Rutas y configuraciones de la imagen de perfil en Facebook. Educació $i$ cultura, 24, 41-73.

Livingstone, S. (2011). Internet, children and youth. En R. Burnett, M. Consalvo y C. Ess (Eds.), The handbook of Internet studies (pp. 348-368). Oxford: Wiley-Blackwell.

Roberts, B. (2011). Photographic portraits: Narrative and memory. Forum Qualitative Sozialforschung / Forum: Qualitative Social Research, 12(2), http://nbnresolving.de/urn:nbn:de:0114-fqs110263

Rueda, R. (2012). Formas de presentación de sí en Facebook. Esbozos de una poética y estética dialógica. Nexus, 12, 202-215.

Rueda, R., y Giraldo, D. (2014). Profile image: ways of self(re)presentation on the Facebook social network. En B. Saegret (Ed.), Youth 2.0: Connecting, Sharing and Empowering. University of Antwerpen, Bélgica, Springer (en prensa).

Sennett, R. (2009). El Artesano. Barcelona: Anagrama.

Sontag, S. (2005). Sobre la fotografía. Bogotá: Anagrama.

Van Dijck, J. (2008). Digital photography: communication, identity, memory. Visual Communication, 7(1), 57-76. 